\title{
O MAPA COMO TEXTO: REFLEXÕES E SENTIDOS NO ESPAÇO URBANO
}

\author{
Julianne Rosy do Valle Satil (PPGEL - UEL) \\ Profa. Dra. Mariângela Peccioli Galli Joanilho (Orientadora)
}

Bem antes de servir para comunicar, a linguagem serve para viver. Se nós colocamos que à falta de linguagem não haveria nem possibilidade de sociedade, nem possibilidade de humanidade, é precisamente porque o próprio da linguagem é, antes de tudo, significar. (BENVENISTE, 1989, p. 222)

\section{RESUMO}

Nossa proposta centra-se na análise do mapa como texto, conforme os estudos da significação desenvolvidos por Eduardo Guimarães, os quais abordam o assunto sob uma perspectiva enunciativa. Para o linguista, autor de Semântica do Acontecimento: um estudo enunciativo da designação (2002), os mapas são assumidos como textos, ou seja, como unidades de sentido, efeitos de linguagem. Nessa perspectiva, as ruas de um bairro, por exemplo, apresentam-se como enunciados que se entrecruzam, sendo passíveis de leitura e interpretação. $O$ processo de interpretação envolve $o$ reconhecimento de que a linguagem não é ingênua, imparcial, sendo atravessada pela ideologia e pela memória. Por isso, mesmo que o mapa apresente-se como documento oficial, aparentemente dotado de neutralidade, sua essência - visto que é linguagem demonstra muito mais do que o óbvio: indicar uma localização ou direção. Desse modo, nomear ruas e organizá-las dentro do mapa são ações políticas, as quais significam os sujeitos, os cidadãos dentro do espaço urbano. Neste trabalho, por meio dos pressupostos teórico-metodológicos da Semântica do Acontecimento, analisaremos a questão já apresentada, tomando a cidade de Londrina como exemplo e sugerindo, também, um trabalho interdisciplinar.

Palavras-chave: mapa, texto, sentidos.

\section{INTRODUÇÃO}

Olhar para a produção de sentidos no espaço da cidade tem sido um dos propósitos de estudos desenvolvidos pelo semanticista Eduardo Guimarães, autor que se debruça sobre o nomear e o designar em um relação integrativa com o mapa. $\mathrm{O}$ mapa, na visão do teórico, é considerado como texto, linguagem. Desse modo, os nomes de ruas e avenidas que o integram são enunciados que movimentam sentidos, os quais significam a todo o momento os cidadãos que vivem na cidade.

Nossa proposta de trabalho filia-se aos pressupostos teóricos da Semântica do Acontecimento, que vem sendo desenvolvida por Guimarães, desde a década de 1980, na Universidade Estadual de Campinas (UNICAMP). Sua teoria propõe caminhos para 


\section{SEMINÁRIO DE PESQUISA EM CIÊNCIAS HUMANAS - SEPECH \\ Humanidades, Estado e desafios didático-científicos \\ Londrina, 27 a 29 de julho de 2016}

se pensar o sentido em um viés enunciativo, trazendo para a discussão elementos de nosso cotidiano, como é o caso do mapa.

Neste trabalho, buscamos apresentar como esse campo teórico pode contribuir para a compreensão do funcionamento da linguagem e como o ensino de língua portuguesa pode ser mais reflexivo, a partir da perspectiva de Guimarães $(2002,2011)$, que sai do lugar-comum e vê o enunciar como ação política, não ao tocante à questão partidária, mas no sentido de que, ao fazê-la, somos significados em um espaço hierarquizado, desigual, onde o sentido nunca está acabado, pronto. Nossa análise será edificada, utilizando como corpus o mapa de Londrina e observando a semantização do enunciado Avenida Higienópolis em uma relação integrativa a esse mapa, na tentativa de possibilitar uma maior reflexão sobre a própria identidade do cidadão londrinense.

\section{SEMÂNTICA DO ACONTECIMENTO: A PERSPECTIVA ENUNCIATIVA DE GUIMARÃES}

Neste momento, faz-se necessária a apresentação de conceitos, que são observados de forma muito particular dentro da Semântica do Acontecimento, são eles: texto e enunciado. Para Guimarães (2011, p.19), texto "é uma unidade de sentido que integra enunciados no acontecimento de enunciação" e enunciado "é um elemento linguístico que tem tanto sentido, integra texto, quanto forma, é constituído por certos elementos (sintagmas)" (GUIMARÃES, 2011, p.21). Em ambas as afirmações, vemos que a relação de integração é enfatizada, visto que é essa relação que possibilita a construção do sentido.

Sobre essa relação, o semanticista, ainda, declara: "a relação de integração se dá porque ela é constituída pela relação de enunciação" (GUIMARÃES, 2011, p. 23). No campo da enunciação, encontra-se o processo de agenciamento do falante, o qual envolve algumas definições, como: Locutor, locutor-x, enunciatário, cena enunciativa, todos conceitos trabalhados por Guimarães (2002).

A cena enunciativa é formada por lugares constituídos pelos dizeres sinalizados por uma temporalização própria de acontecimento. São espaços circunscritos em princípios morais e éticos, que determinam a distribuição de papéis sociais, de lugares da enunciação no acontecimento. É na cena enunciativa que se estruturam formas de acesso à palavra, é onde se estabelece a relação entre os lugares de enunciação e as formas linguísticas. Segundo Guimarães (2002, p. 23), "assumir a palavra é pôr-se no lugar que enuncia" e ao configurar a cena enunciativa, o teórico delineia, também, duas instâncias enunciativas: Locutor e enunciador.

Para Guimarães (2002), o Locutor (com L maiúsculo) é a fonte do dizer, fundamentada pelo sentido. Na enunciação, há o desdobramento de $L$ em locutor-x (seu lugar social), que o autoriza a falar de um modo específico. O Locutor só se constitui como tal, pois ocupa um lugar socialmente demarcado, desse modo, "a figura do Locutor é díspar entre si” (GUIMARÃES, 2002, p. 24).

$\mathrm{O}$ enunciador surge como lugar de dizer do Locutor. Enquanto enunciador, o Locutor, atravessado pelo esquecimento de que fala de um lugar específico, divide-se como se enunciasse de algum lugar meramente do dizer. Esses lugares de dizer são o que Guimarães define como enunciadores, "se apresentam sempre como a representação da inexistência dos lugares sociais de locutor.” (GUIMARÃES, 2002, p.26) Os 


\section{SEMINÁRIO DE PESQUISA EM CIÊNCIAS HUMANAS - SEPECH \\ Humanidades, Estado e desafios didático-científicos \\ Londrina, 27 a 29 de julho de 2016}

enunciadores podem ser de quatro tipos: individual (como em "eu escrevo..."); universal (comum no discurso da ciência, sem modalizações); genérico (como na repetição de um ditado popular) e coletivo (como em "nós, acadêmicos...").

Assumir o mapa como texto e suas ruas como enunciados, envolve, também, o pensar sobre a nomeação e a designação, visto que esses enunciados no mapa são nomes próprios.

A nomeação "é o funcionamento semântico pelo qual algo recebe um nome." (GUIMARÃES, 2002, p.9). Costa (2004, p.33) retoma o conceito, acrescentando que

[...] a nomeação seria a enunciação fundadora, aquilo que só ocorre, num certo sentido, uma única vez; a partir daí o que há são referências e a reconstituição incessante das designações numa forma de conseqüência dessa enunciação fundadora. Nomear é um processo de identificação social, é recortar o real e dá-lhe uma identidade, como uma forma de construir o sentido do visível, em que se toma a significação a partir do nome.

A designação encontra-se no espaço da constituição de sentido, é como o nome significa no acontecimento e como esse nome pode mobilizar e assumir sentidos ao longo da história. Para o filósofo Jacques Rancière (1994), um nome não classifica, ele identifica, apresentando-se como um recorte do mundo, construindo o sentido do objeto, por isso, o nome constitui um enunciado carregado de historicidade, significação e identidade. Assim, o nome de rua (re)significa o espaço nomeado, conferindo-lhe existência histórica e é isso que o permite significar.

Consoante a Rancière (1994), Guimarães (2003) aborda a designação dentro do espaço urbano, afirmando que "Os nomes de espaço na cidade, e o que os acompanha, não só ocupam lugar neste espaço de vida, como lhe dão sentidos e constroem de algum modo esta geografia. Identificam-na." (GUIMARÃES, 2003, p. 54)

Nesse sentido, Guimarães $(2002$, p.9) considera que a designação se relaciona à

significação de um nome, mas não enquanto algo abstrato. Seria significação enquanto algo próprio das relações de linguagem, mas enquanto uma relação linguística (simbólica) remetida ao real, exposta ao real, ou seja, enquanto uma relação tomada na história.

A designação é, portanto, um acontecimento enunciativo, sendo exterioridade produzida pela linguagem, constituída pelo confronto de discursos. Compreendemos, dessa maneira, que a designação e a nomeação são processos intimamente relacionados, envolvendo a relação entre enunciações, entre acontecimentos de linguagem.

Ao considerar a língua e sua historicidade, a Semântica do Acontecimento oportuniza um dispositivo teórico-analítico da designação dos nomes de ruas de Londrina, trazendo um olhar diferenciado a um texto não convencional, não cristalizado - o mapa. 


\section{SEMINÁRIO DE PESQUISA EM CIÊNCIAS HUMANAS - SEPECH \\ Humanidades, Estado e desafios didático-científicos \\ Londrina, 27 a 29 de julho de 2016}

\section{O MAPA COMO LINGUAGEM}

Dentro de sua Semântica do Acontecimento, conforme já expusemos anteriormente, Guimarães (2011) assume o texto como unidade de sentido integrada por enunciados. Unidade, pois é finito em extensão, não significando, dessa maneira, que seu sentido seja único. Na realidade, os sentidos do texto (mapa) podem ser múltiplos.

O mapa é muito mais que um uma ilustração, que traz em si localizações de logradouros, entre os quais nomes de ruas e avenidas, não é um documento neutro, por ser linguagem, é marcado pela ideologia. Ideologia que atravessa sua organização, que atravessa a distribuição de seus enunciados (nomes de ruas), portanto, "esses nomes estão vinculados uma representação do espaço da cidade." (GUIMARÃES, 2011, p.20).

Pensar o mapa como texto desvia de uma perspectiva tradicional, Guimarães (2002) defende que este documento pode conter mais informações do que uma narração ou descrição, trazendo em si a história da cidade. Os nomes de ruas e avenidas que integram o mapa, também, trazem essa história, a qual é realçada pelos nomes distribuídos no mapa. Na mesma perspectiva de Guimarães, Rasia (2006, p.181) declara que o mapa é "a radiografia da cidade", revelando sentidos que estão presentes, mesmo que silenciados, mas que exigem sensibilidade em sua leitura e interpretação.

Desse modo, analisar o mapa de Londrina e os nomes de logradouros que o integram, possibilita uma maior reflexão sobre o que é ser cidadão londrinense, assim como sua história, sua memória.

\section{AVENIDA HIGIENÓPOLIS E A REPRESENTAÇÃO DA BURGUESIA LONDRINENSE}

No enunciado Avenida Higienópolis temos uma questão etimológica. Higienópolis é um nome constituído por dois nomes diferentes (higiene + polis), os quais se aglutinam, formando uma nova palavra que funciona como nome próprio de um endereço em Londrina. Temos, assim, um nome formado por mais de uma enunciação, sendo necessário, portanto, que nos atentemos aos sentidos produzidos por esses enunciados.

O primeiro deles, higiene, tem sua origem no nome da deusa grega da saúde, também, símbolo da Farmácia, Hígia (filha de Asclépio, deus grego da Medicina) e remete a um memorável de limpeza e salubridade. O segundo nome, polis, palavra, também, de origem grega designa cidade, compreendida como espaço urbano e social que permite aos cidadãos conviverem e relacionarem-se.

Com a aglutinação das duas palavras, temos, então, como sentido do nome "cidade da limpeza", "lugar da limpeza", o que é justificado, no acontecimento de nomeação da avenida, na década de 1930, pela sua localização que se encontra em um ponto alto, sendo, desse modo, um local mais limpo que os demais, com menor possibilidade de doenças em comparação ao restante dos lugares da cidade.

No mapa a seguir, podemos verificar a localização do logradouro, que perpassa as ruas mais antigas da cidade (as quais receberam nomes de estados brasileiros), componentes do Centro Histórico. 


\section{SEMINÁRIO DE PESQUISA EM CIÊNCIAS HUMANAS - SEPECH \\ Humanidades, Estado e desafios didático-científicos \\ Londrina, 27 a 29 de julho de 2016}

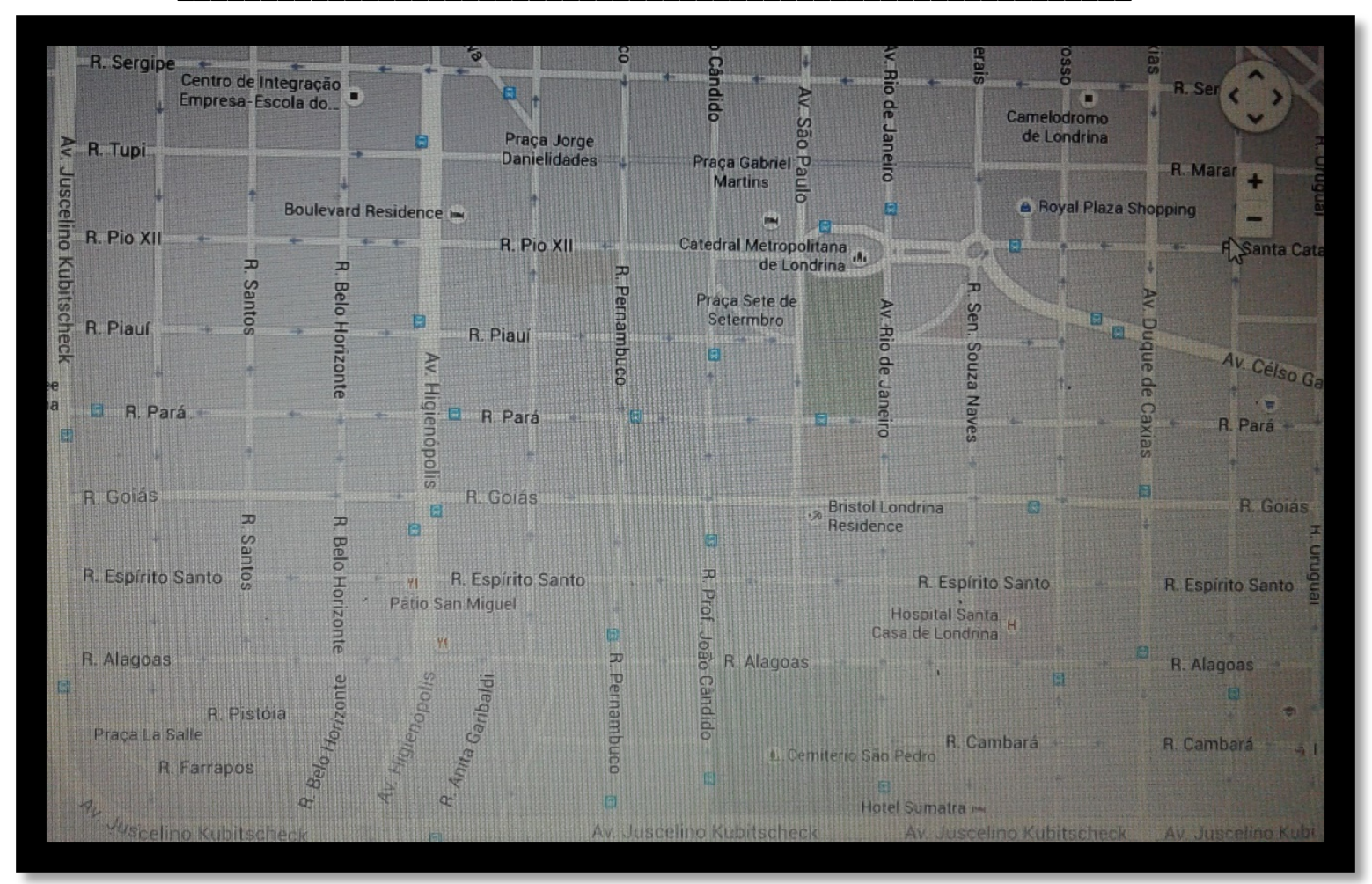

Figura 1 - Localização da Avenida Higienópolis

Fonte: Google Maps

Sobre a escolha do território para ser nomeado de Avenida Higienópolis, ação que não ocorreu aleatoriamente, Silva e Boni $(2009$, p. 3) declaram:

Seu traçado original foi concebido por Mr. Arthur Thomas - diretor presidente da CTNP - inspirado no bairro aristocrático (Higienópolis) de São Paulo. Mr. Thomas cedeu às insistências do russo Eugênio Victor Larionoff, também diretor da CTNP e seu secretário particular (cuja família residia no bairro paulista), e de George Craig Smith, que reivindicavam sua abertura. Como Londrina, na época, só possuía avenidas estreitas, a ideia foi projetar uma avenida larga, com alamedas e jardins. O local escolhido não foi por acaso: era o ponto mais alto da cidade, o mais arejado, livre das epidemias que ocorriam no centro do núcleo urbano, portanto o local mais "higiênico".

O acontecimento de nomeação de Avenida Higienópolis apresenta como característica de sua cena enunciativa o lugar do sujeito da administração municipal; o Locutor que enuncia predica o lugar social do locutor-legislador que assimila o lugar de dizer de um enunciador heterogêneo que fala da perspectiva político-jurídica do município e da mitologia grega. Há, portanto, nessa situação, o enunciador constituído pelo lugar de dizer do enunciador-universal.

A enunciação designativa que nomina Avenida Higienópolis se mostra como nome e, no seu funcionamento enunciativo, temporaliza o seu próprio presente do acontecimento que acaba por constituir o sentido primeiro desse nome (a avenida), que abre em si sua latência de futuro e traz, também, a enunciação que recorta como memorável a mitologia grega, elemento que passa a significar diretamente na 


\section{SEMINÁRIO DE PESQUISA EM CIÊNCIAS HUMANAS - SEPECH \\ Humanidades, Estado e desafios didático-científicos \\ Londrina, 27 a 29 de julho de 2016}

determinação do nome desse logradouro público. Assim, Avenida Higienópolis designa um espaço urbano que é identificado como componente da rotina político-legislativa de Londrina e que é determinado por uma intenção etimológica.

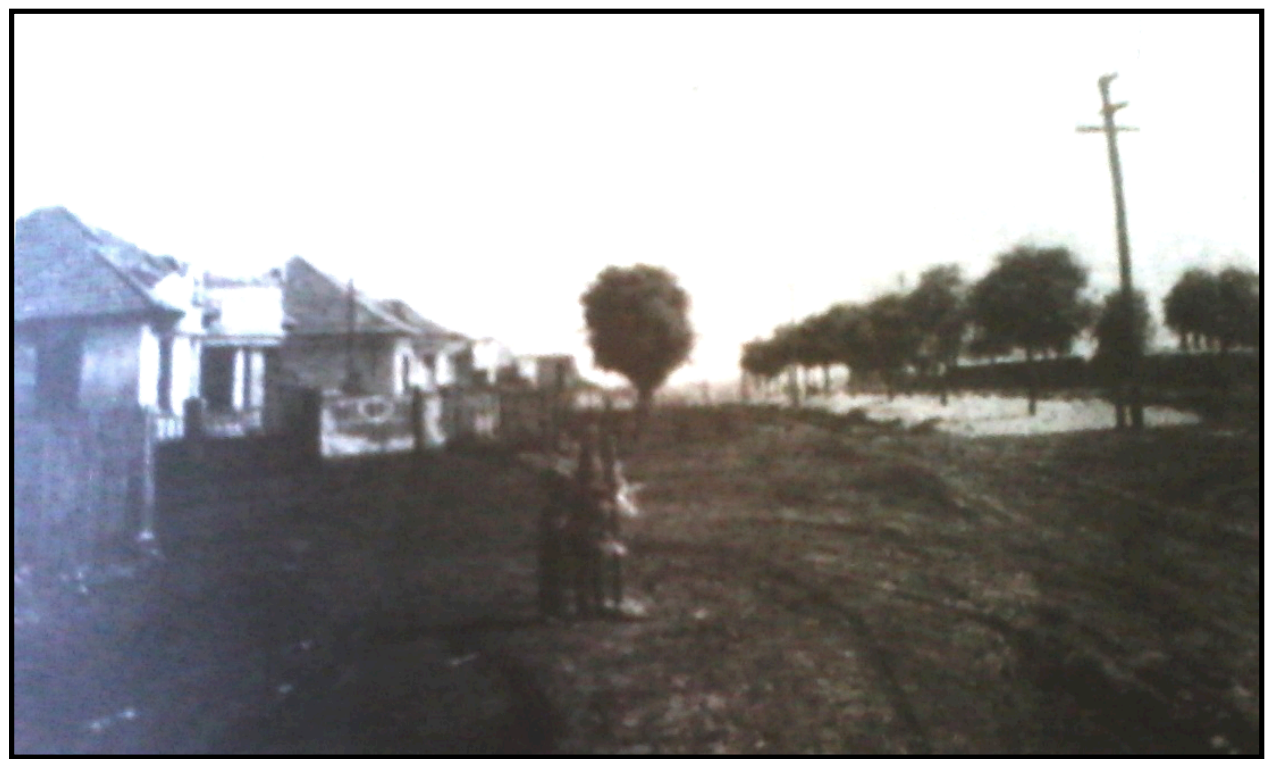

Figura 2 - Avenida Higienópolis em 1941

Fonte: BORTOLOTTI, 2007, p. 51

Inspirada no bairro paulistano Higienópolis, a avenida foi projetada e edificada para satisfazer o desejo da classe burguesa, tornando-se um território de famílias influentes da sociedade londrinense. Como pode ser observado no excerto e na foto que se seguem.

Dessa forma, nos anos 1930, a Avenida Higienópolis era um projeto de transposição do estilo de vida de São Paulo para o hinterland ${ }^{l}$ do Paraná. Nos anos 40, mas, sobretudo, nas décadas de 50 e 60, ela espelhava o aburguesamento da vida citadina [...] As casas de muros baixos com jardins bem cuidados criavam um cenário em que as famílias ainda não se escondiam do mundo público. Contudo, era um território exclusivo de algumas famílias notáveis da cidade. (SILVA; BONI, 2009, p.2)

\footnotetext{
${ }^{1}$ Hinterland é um termo da língua alemã, utilizado pela Geografia Urbana. O equivalente em língua portuguesa é hinterlândia e refere-se a "Todas aquelas áreas agrícolas que cedem à cidade (sob a forma de vendas de mercadorias, pagamento de impostos, oferendas religiosas, etc) parte de seu excedente e consomem, em alguma medida, bens ou serviços da cidade". (SINGER, 1968, p.7). Assim, de acordo com essa perspectiva, o termo hinterlândia refere-se a uma relação e interação baseada na interdependência entre dois tipos de espacialidades - o centro urbano (papel desempenhado por Londrina) e os demais núcleos secundários -, que se baseia na esfera econômica, mas que vai além dela, incluindo elementos culturais, sociais e político-institucionais.
} 


\section{SEMINÁRIO DE PESQUISA EM CIÊNCIAS HUMANAS - SEPECH \\ Humanidades, Estado e desafios didático-científicos \\ Londrina, 27 a 29 de julho de 2016}

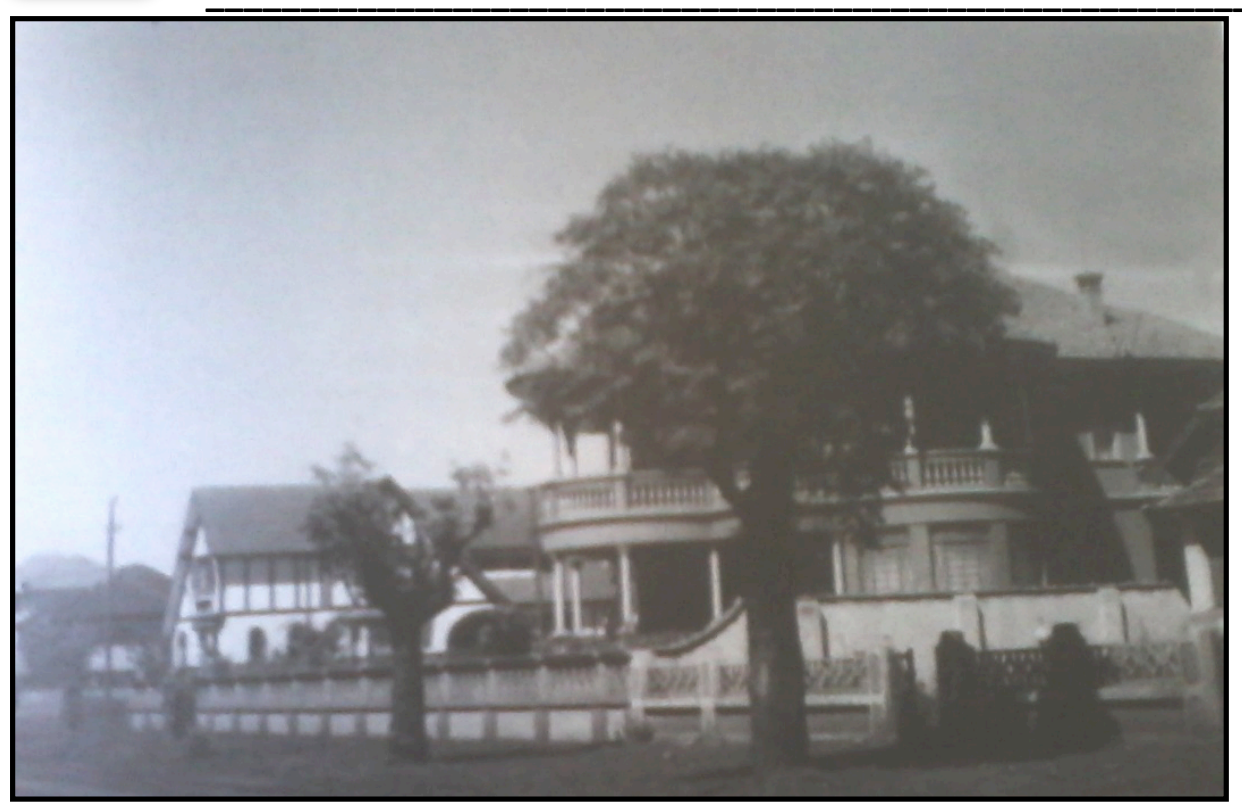

Figura 3 - Palacete na Avenida Higienópolis na década de 1940

Fonte: YAMAKI, 2006, p. 51

Essa mesma perspectiva é assumida por Grassiotto e Grassiotto (2003, p.109) quando afirmam:

Na década de 40, a Av. Higienópolis, cortando a cidade do centro para o Sul, apresentou-se como uma área diferenciada, abrigando as primeiras residências dos homens ilustres, os barões do café, e assim transformou-se na zona residencial mais elegante daquele momento. A avenida foi construída como um retrato das mansões das Avenidas Paulista e Brasil (em São Paulo), reproduzindo a cultura burguesa daquela fase eclética da arquitetura brasileira.

Yamaki (2006), ao tratar das paisagens urbanas de Londrina, faz, também, uma análise do processo de criação da avenida:

A adoção do topônimo Hygienopolis ou "Cidade da Higiene" fazia parte de um processo de construção de imagem de "cidade idealizada" que havia sido iniciado por Razgulaeff. Justifica-se assim a indicação de "alamedas e jardins", no plano inicial. Uma cidade com alamedas e jardins e uma aristocrática avenida! Tentativa de construção de uma metrópole à imagem de grandes capitais. A Hygienopolis de Londrina é portanto, indissociável da avenida de igual nome em São Paulo, um loteamento de chácaras do final do século XIX que fora ocupado por palacetes de barões do café. O local era alto e de bom clima, livre de epidemias que ocorriam no centro. Logo, o nome dava idéia de um lugar aristocrático e saudável, adequado à aplicação [...] Fotografias da época [1941] mostram palacetes de linguagens arquitetônicas variadas, soltos nas datas e cercados por muros baixos compostos de peças trabalhadas em pré-moldados de concreto. (YAMAKI, 2006, p.50) 


\section{SEMINÁRIO DE PESQUISA EM CIÊNCIAS HUMANAS - SEPECH \\ Humanidades, Estado e desafios didático-científicos \\ Londrina, 27 a 29 de julho de 2016}

Entretanto, mesmo com todo glamour atribuído à avenida, sendo residência da alta sociedade londrinense, há de se considerar, também, os que não faziam parte desse grupo social. O processo de ocupação de Londrina foi repleto de conflitos, os quais foram silenciados pelo discurso colonizador. Sobre isso, Tomazi (1997) apresenta uma reflexão coerente, alertando para o confronto de discursos presentes no espaço londrinense no início da formação de Londrina.

Ao discurso de que a (re)ocupação foi pacífica contrapõe-se um outro discurso: o daqueles que sofreram a violência e a exclusão. Ao discurso de que a região situada ao norte do estado do Paraná foi e é um "Novo Canaã", um novo "Eldorado", contrapõe-se o discurso daqueles que chamavam a Av. Higienópolis, em Londrina, de "Lágrimas de Lavrador", pois ali moravam muitos fazendeiros. (TOMAZI, 1997, p. 106)

Portanto, além da questão político-legislativa e da mitologia, Avenida Higienópolis recorta, também, como memorável o ideal burguês e o status social representados pelo bairro paulistano de mesmo nome. O que vemos, mesmo que de forma velada, é um espaço de confrontos:

A sociedade capitalista em seu funcionamento contemporâneo é uma sociedade que vai além da exclusão, ela funciona pela segregação (coloca para fora da sociedade, e, quem está fora, não existe, não é levado em conta) [...] A mesma palavra não significa a mesma coisa para o patrão e para o empregado [...] (ORLANDI, 2011, p. 696)

Nesse sentido, se de um lado Avenida Higienópolis é sinônimo de status socioeconômico, local em que residiram os "Barões do Café", a aristocracia; de outro, é as "Lágrimas de Lavrador" que demonstram o sentimento do segregado, do explorado. O nome, desse modo, movimenta sentidos distintos, opostos, evidenciando uma relação pautada no sofrimento de muitos - lavradores - que visava ao favorecimento de poucos - a burguesia cafeeira. Temos sentidos diferentes, designações distintas, os quais retomam, por meio de reescrituração, o mesmo nome - Avenida Higienópolis.

Ainda na atualidade, Avenida Higienópolis é sinônimo de burguesia, mesmo havendo outros bairros, muitos deles bem mais novos, que são significados como da alta sociedade de Londrina, como parte "nobre" da cidade. Na memória do povo, a Avenida Higienópolis ainda é um lugar significado de forma diferente dos demais integrantes do espaço urbano londrinense, perpetuando-se como reduto da população abastada da cidade. Não são mais os barões do café que moram lá, mas sim muitas famílias tradicionais, detentoras de um poder aquisitivo acima da média da população, donas de um elevado padrão de vida.

\section{UMA PROPOSTA INTERDISCIPLINAR}

Para conseguirmos investigar o processo de designação, assumimos, conforme já apresentamos, o mapa como texto. Isso significa que "tomar o mapa como texto, é considera-lo como linguagem, sentido" (GUIMARÃES, 2002, p.59). A Semântica do 


\section{SEMINÁRIO DE PESQUISA EM CIÊNCIAS HUMANAS - SEPECH \\ Humanidades, Estado e desafios didático-científicos \\ Londrina, 27 a 29 de julho de 2016}

Acontecimento, que se ocupa do sentido em um viés enunciativo, nasce de uma perspectiva interdisciplinar, sendo influenciada, principalmente, pela Análise de Discurso de linha francesa e pela Semântica Argumentativa.

Por isso, trabalhar sob a ótica enunciativa dentro do contexto escolar, assumindo o mapa como texto, é olhar para as relações que integram esse mapa, relações que nem sempre são respondidas pela linguagem, mas que partem sempre da linguagem. A teoria de Guimarães propicia um trabalho com vários campos do saber, referências que compuseram a análise desenvolvida. Nela, constam conhecimentos advindos da geografia, história, sociologia e linguística.

Sendo assim, diversas disciplinas da grade curricular podem se unir para compor o processo de leitura e interpretação do mapa, são exemplos: a língua portuguesa, a sociologia, a filosofia, a geografia e a história. Uma pesquisa que possibilita a ampla reflexão de alunos e professores que conseguirão perceber que a todo momento estão sendo significados por onde moram, trabalham ou estudam. Por isso, estudar o mapa em uma perspectiva enunciativa é civilizar-se, sendo importante sua aplicação em sala de aula.

Para encerrarmos este momento de nosso texto, utilizaremos uma citação de Gesualda Rasia, que ilustra muito bem a dimensão das contribuições de Guimarães para os estudos enunciativos da significação, os quais podem se estender, também, ao universo escolar.

Com maestria Guimarães fornece as pistas para se recomporem as histórias enunciativas opacificadas em nomes próprios, os quais, partícipes do processo de subjetivação pelo qual o indivíduo é identificado consigo mesmo, produzem efeito de unicidade. As ruas, lugares por onde circulam as pessoas, são identificadas pela historicidade que seus nomes evocam, não como mera lembrança de acontecimentos, mas como materialização da condição simbólica da linguagem, fazendo significar inclusive a partir do que é calado nos processos de designação. (RASIA, 2006, p.182)

\section{CONSIDERAÇÕES FINAIS}

Neste trabalho, propusemos o pensar sobre um texto presente em nosso cotidiano - o mapa - analisando-o por um viés diferente. Tratando o mapa como texto, em que os nomes o integram e mobilizam sentidos, percebemos como é construída a significação da identidade de seus cidadãos. Sentidos que são determinados com relação às distintas regiões que formam a própria cidade de Londrina.

$\mathrm{O}$ enunciado que analisamos, Avenida Higienópolis, dentro do espaço londrinense, é semantizado de modo particular, distinto, se comparado a uma rua de bairro periférico. O nível de prestígio não é o mesmo e seu status tem se evidenciado ao longo da história da cidade. Ainda hoje, o lugar é superestimado. Essas distinções também identificam os sujeitos que residem nesse espaço, por isso, o local de residência determina o sujeito, sendo parte de sua identidade citadina.

Apresentamos, também, uma proposta interdisciplinar de leitura e interpretação, que pode mobilizar disciplinas diversas do currículo escolar, possibilitando um trabalho 


\section{SEMINÁRIO DE PESQUISA EM CIÊNCIAS HUMANAS - SEPECH \\ Humanidades, Estado e desafios didático-científicos \\ Londrina, 27 a 29 de julho de 2016}

de grande valia na construção de cidadãos críticos e reflexivos sobre a realidade que o cercam.

\section{REFERÊNCIAS}

BENVENISTE, E. Problemas de linguística geral II. Campinas-SP: Pontes, 1989.

BORTOLOTTI, J. B. Planejar é preciso: memórias do planejamento urbano de Londrina. Londrina: Midiograf, 2007.

COSTA, F. C. V. Designação e referência: Uma análise enunciativa no Censo demográfico 2000. 77 f. Dissertação (Mestrado em Linguística. Área de Concentração: Semântica) - Instituto de Estudos da Linguagem, Universidade Estadual de Campinas, Campinas, 2004.

GRASSIOTO, M.L.F; GRASSIOTTO, J.A. de. A atividade comercial e sua relação com o urbano: o exemplo de Londrina. Semina. Londrina, v. 24, set/2003. Disponível em

$<$ http://www.uel.br/proppg/portal/pages/arquivos/pesquisa/semina/pdf/semina_24_1_21 43.pdf>. Acesso em 22 abr. 2016.

GUIMARÃES, E. Análise de texto: procedimentos, análises, ensino. Campinas: Editora RG, 2011.

Designação e espaço de enunciação: um encontro político no cotidiano. Letras (UFSM). Língua e literatura: limites e fronteiras. Santa Maria-RS, n. 26, jun/2003, p. 53-62. Disponível em <http://cascavel.ufsm.br/revistas/ojs-2.2.2/index.php/letras>. Acesso em 02 dez. 2015.

- Semântica do Acontecimento: um estudo enunciativo da designação. Campinas: Pontes, 2002.

ORLANDI, E. P. A casa e a rua: uma relação política e social. In: Revista Educação e Realidade. Porto Alegre, v.36, n. 3, p. 693-703, set/dez. 2011. Disponível em: $<$ http://www.ufrgs.br/edu_realidade $>$. Acesso em 16 mar. 2016.

RANCIÈRE, J. Os nomes da história: um ensaio da poética do saber. Trad. Eduardo Guimarães, Eni Orlandi. São Paulo: EDUC/Pontes, 1994.

RASIA, G. Semântica do Acontecimento: um olhar sobre a cidade, seus nomes e suas práticas políticas. Conexão Letras. Porto Alegre, v. 02, n.02. Disponível em $<$ http://www.artistasgauchos.com/conexao/2/cap12.pdf $>$. Acesso em 14 maio 2016.

SILVA, S. H.; BONI, P. C. Avenida Higienópolis: Um retrato da burguesia londrinense nas décadas de 30, 40, 50 e 60. Fortaleza, 2009. Disponível em 


\section{SEMINÁRIO DE PESQUISA EM CIÊNCIAS HUMANAS - SEPECH \\ Humanidades, Estado e desafios didático-científicos \\ Londrina, 27 a 29 de julho de 2016}

$<$ http://www.ufrgs.br/alcar/encontros-nacionais-1/7o-encontro-2009-1/>. Acesso em 27 abr. 2016.

SINGER, P. Desenvolvimento econômico e evolução urbana. São Paulo: Editora Nacional, 1968.

TOMAZI, N. D. Norte do Paraná: história e fantasmagorias. 338f. Tese (Doutorado em História), Universidade Federal do Paraná, Curitiba, 1997.

YAMAKI, H. Labirinto da memória: paisagens de Londrina. Londrina: Humanidades, 2006. 